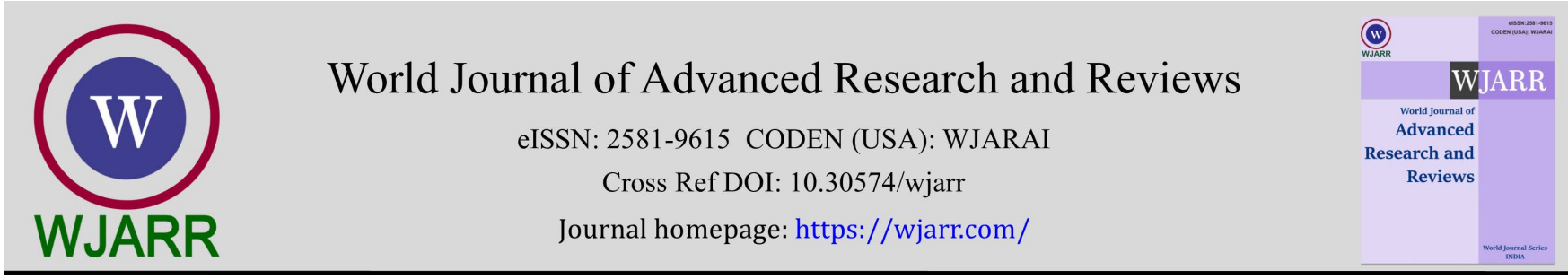

(CASE REPORT)

Check for updates

\title{
Double caustic, esophagic and pyloric stenosis post-ingestion of soda: Rare case
}

Monsoia Gildas Yassegoungbe 1, *, Médard Ayawo Guedenon 1 , Codjo Serge Metchihoungbe 2, Mondukpé Grace Immaculée Sergine Dossou 1, Mahussi Henok Orion Akokpe 1, Mahunakpon Vihotogbé Léon Samuel Boris Gogan ${ }^{1}$, Géraud Garcia Philemon Satingo Segbedji ${ }^{1}$, Aldrico Pautin Covi ${ }^{2}$ and Antoine Seraphin Gbenou ${ }^{1}$

\section{${ }_{1}$ Pediatric Surgery Department of the Lagune Mother and Child University Hospital (CHU-MEL)/Cotonou Benin. \\ 2 University Clinic of Pediatric Surgery of the National Hospital and University Center Hubert Koutoukou Maga (CNHU- HKM)/Cotonou/Benin.}

World Journal of Advanced Research and Reviews, 2021, 10(02), 039-043

Publication history: Received on 01 April 2021; revised on 05 May 2021; accepted on 07 May 2021

Article DOI: https://doi.org/10.30574/wjarr.2021.10.2.0203

\begin{abstract}
The ingestion of caustic soda is frequently a source of complications. Esophageal stenosis remains among them the most frequent complication and by far the most formidable. Pyloric stenosis remains rare following ingestion of soda. We report through this clinical case, a cicatricial pyloric stenosis after ingestion of caustic soda associated with a stenosis of the esophagus having caused vomiting with the onset of severe malnutrition. The diagnosis was confirmed by the oeso-gastro-duodenal transit (OGDT) and the child underwent under general anesthesia an enlargement pyloroplasty according to Mikulicz initially and an esophageal dilation secondly to the candle of SAVARY. The postoperative followup was favorable with an improvement of the signs and a progressive postoperative weight gain after a follow-up of 06 months. The evolution was favorable after the monthly dilation sessions with a good resumption of transit.
\end{abstract}

Keywords: Stenosis; Soda; Caustic; Esophagus; Pylorus

\section{Introduction}

The ingestion of caustic substances is a real public health problem in Africa [1]. It is a common accident in children. It is a medico-surgical emergency with high morbidity and mortality due to the various lesions it causes and their repercussions [2,3]. Lesions caused by ingestion of bases are generally esophageal unlike acids which are sources of gastro-pyloric lesions [3]. We report a case of genuine pyloric stenosis after ingestion of caustic soda associated with esophageal stenosis in a 2-year-old boy.

\section{Observation}

This is a 2-year-old male child referred from a nearby health center for malnutrition due to dyspeptic disorder after ingestion of caustic soda. The history of the incident was four weeks before admission. The child is said to have accidentally swallowed about $40 \mathrm{cc}$ of caustic soda for the preparation of local soap at home. It would have followed a few days later, a retro-sternal pain with dysphagia to the solids then to the liquids for which the child benefited from the installation of a nasogastric feeding tube on the $5^{\text {th }}$ day after ingestion in a Health center. The evolution was marked by the occurrence of vomiting around the nasogastric tube after feeding which caused progressive malnutrition over 3 weeks, amounting to $3 \mathrm{~kg}$. On admission, the infant presented an altered general condition with poor nutritional status, the weight / height ratio less than -3 standard deviation (weight at $7.5 \mathrm{~kg}$ and height at $84 \mathrm{~cm}$ ). Sialorrhea was noted on an existing nasogastric tube 10 . The abdomen was flat with skin folds from malnutrition. In front of this table, a nutrition

\footnotetext{
* Corresponding author: Monsoia Gildas Yassegoungbe

Pediatric Surgery Department of the Lagune Mother and Child University Hospital (CHU-MEL)/Cotonou Benin. 
plan was set up with enriched porridge given by the nasogastric tube at the rate of $10 \mathrm{cc} /$ hour. This plan was unsuccessful because vomiting persisted despite feeding through a nasogastric tube.

An oeso-gastro-duodenal transit, nasogastric tube in place was carried out 7 weeks after ingestion of soda showing a stenosis of the pylorus with a stomach of stasis, a narrowed pyloric duct filiform with a fall of the barite in flakes of snow (figure 1).

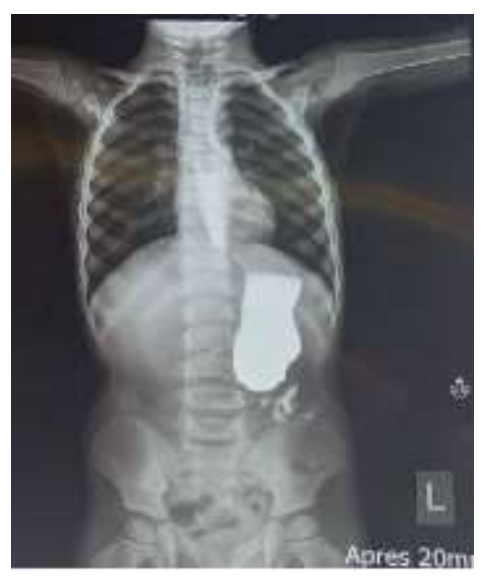

Figure 1 Stomach of stasis, a narrowed pyloric duct filiform

Caustic pyloric stenosis was therefore diagnosed, indicating surgical management. We perform a median umbilical laparotomy, objectified a stenotic and indurated pylorus. We decided to perform a longitudinal pylorotomy over $3 \mathrm{~cm}$ allowing to see a pyloric mucosa with a fibrotic appearance, reworked over $1.5 \mathrm{~cm}$ with the pyloric antrum and the distal end of the pylorus covered with healthy-looking mucosa. Transverse pyloroplasty is performed on a parent probe pushed through the pylorus to jejunal level and left in place (Figure 2).

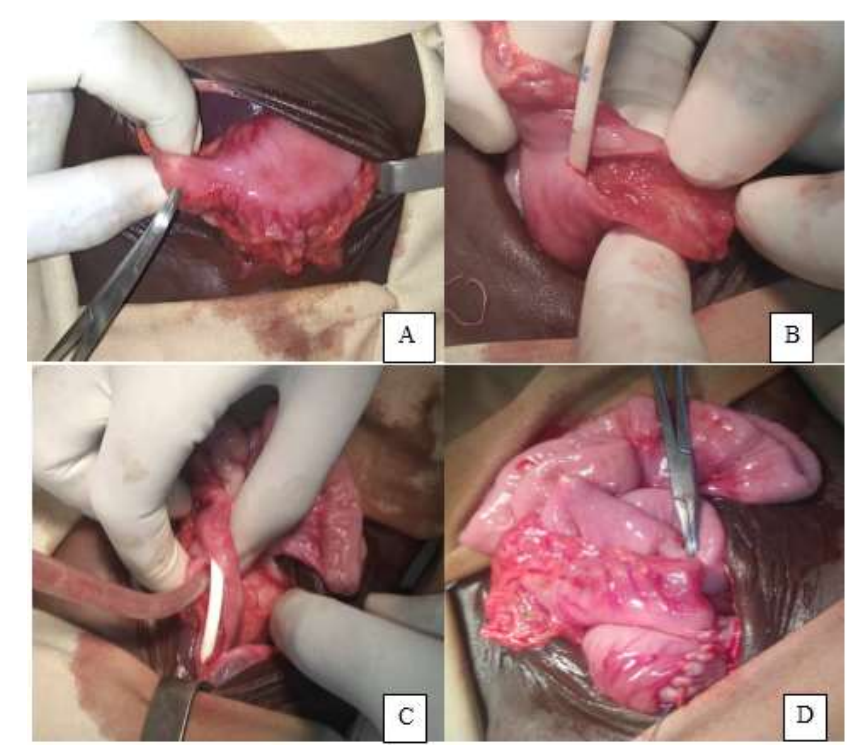

Figure 2 Pyloroplasty of Heineck Mikulicz. A. Stenotic and indurated pylorus; B. Pyloric mucosa with fibrotic appearance reworked over $1.5 \mathrm{~cm}$; C. Placement of the jejunal probe at the level of the pylorus before the plasty; D. Heineck-Mikulicz transverse suture.

The postoperative outcome was favorable with resumption of food on the first postoperative day through the jejunal tube, without vomiting; a weight gain of 2500 grams after one (01) month of postoperative follow-up. At the $5^{\text {th }}$ week post pyloroplasty, a OGDT was performed after ablation of the jejunal probe showing a narrowing of the esophagus at $\mathrm{T}_{4}-\mathrm{T}_{5}$ and at the level of the cardia (Figure 3 ). 


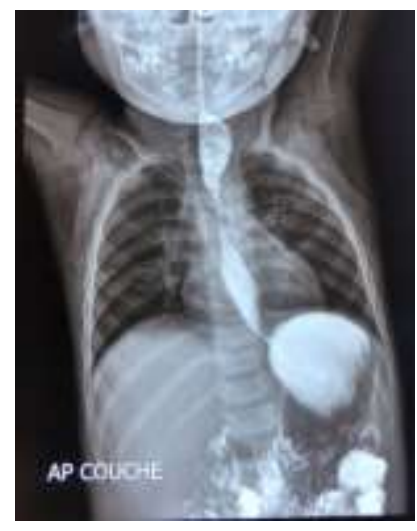

Figure 3 Staged esophageal stenosis, height of $\mathrm{T}_{4}-\mathrm{T}_{5}$ and at the level of the cardia, good intestinal opacification

The infant benefited from a series of esophageal dilation with the flexible candle of SAVARY GUILLARD once a week for 4 weeks. The outcome was favorable with disappearance of dyspeptic disorders and sialhorrhea after a 6-month followup with good weight gain.

\section{Results and discussion}

The ingestion of caustic, because of its severity and its undervalued frequency is currently recognized by the World Health Organization (WHO) as being an unrecognized violence against children and which is totally neglected in developing countries [2]. Soda is the caustic mainly ingested in Africa because of its current use by our mothers in the artisanal manufacture of soap and often left within the reach of children [3]. Caustics create esophageal lesions that develop from ulceration to complete scarring, causing narrowing or even complete obstruction of the esophageal lumen [3]. Pyloric stenosis caused by soda is therefore very rare [4]. The literature reports the acid as the product most involved in pyloric lesions [4]. The first case of pyloric stenosis by ingestion of a corrosive substance (sulfuric acid) was reported by ROBERT in 1828 [4]. Quénu and Petit, in their review found reports of 84 cases in which ingestion of corrosive substances had caused pyloric obstruction; of which 5 cases were due to ingestion of caustic. Zinc chloride was the cause of the obstruction in one case, while copper sulfate was the cause of the other lesions [5]. Other corrosive substances reported to have caused pyloric stenosis are potassium hydroxide and formaldehyde. In addition, esophageal stenosis was present in all cases [5].

The clinical data found in this case are similar to those of other authors [6,7]. Indeed, a rigorous questioning confirms the effective ingestion of the corrosive product. The infant in our observation had ingested $40 \mathrm{cc}$ of soda; not insignificant quantity. Sialorrhea, labio-oral lesions and vomiting were the lesions observed during the initial phase, while dysphagia was the main reason for consultation found in all children with stenosis of the esophagus. The installation of a nasogastric tube made it possible to delay these signs in the present clinical case and made it possible to camouflage the esophageal stenosis often formed around four (04) to six (06) weeks after ingestion [8], making the diagnosis of secondary esophageal stenosis.

Persistent weight loss and vomiting despite the nasogastric tube in place were the reasons for carrying out the first OGDT, which made it possible to make the diagnosis of pyloric stenosis in this case. This is often a diagnosis often made despite the clinical history as it develops a few years later [9] but in this case this diagnosis was primary.

The acidic $\mathrm{pH}$ of the stomach will explain the rarity of caustic pyloric stenosis in the case of ingestions of caustic soda. Indeed, the stomach thanks to the activity of the parietal cells secretes hydrochloric acid ( $\mathrm{HCl})$. The latter has a $\mathrm{pH}$ between 1 and 2 [10]. The amount of acid produced depends on the foods eaten, their quantities and is reduced in the event of an emptiness of the stomach. Since the $\mathrm{pH}$ of caustic soda is basic $(\mathrm{pH}=14)$ [10], it is neutralized by this gastric acidity of the stomach, which explains the rarity of gastro-pyloric lesions. In our case, the lack of financial means would be a factor favoring pyloric stenosis because the starving child has a less acidic $\mathrm{pH}$ which cannot buffer the soda ingested. The stagnation of the still basic solution at the level of the pyloric antrum would then be the cause of the fibrosis objectified during the operation. In this case, the lack of funding for care and scientific research hampered the pathological exploration of the fibroid pyloric mucosa remnant. However, this mucous membrane residue was left in place for the plasty. 
The different types of pyloroplasty which have been described by Mikulicz, Finney and Judd [11], may find a place in the treatment of pyloric stricture. It depends on the local condition of the tissues and the extent of the pathological process. These interventions are indicated in cases of localized scarring of the anterior pyloric wall [12]. In cases where healing is more extensive, the need to suture through scarred and indurated tissue, even in part of the incision, would make its use less desirable and would immediately indicate a gastro-jejunostomy. In the case we have reported, given the stenosis which extended just over $1.5 \mathrm{~cm}$ and the mucosa intact at the level of the antrum and the terminal part of the pylorus, an enlargement pyloroplasty according to Mikulicz was performed with in place of a guardian probe [11] Figure 4. This makes it possible to have a short but good-sized pylorus filled with normal mucosa downstream and upstream from the fibrosis. The satisfactory follow-up with good intestinal opacification after the second OGDT shows the effectiveness of this technique in the management of caustic pyloric stenosis.

The nasogastric tube, put in place early and replaced by the jejunal tube, made it possible to direct the healing of the esophageal lesions, which initially allowed to correct the malnutrition and facilitate the management of the stenosis. Several candles have been used over time but the most widely used today are those of SAVARY GUILIARD and REHBEIN [13]. The REHBEIN candle was more efficient and did not require a fluoroscopy [13]. It is unavailable, which motivated the use of the SAVARY GUILIARD candle as several authors $[14,15]$ have done with a good result as in our case.

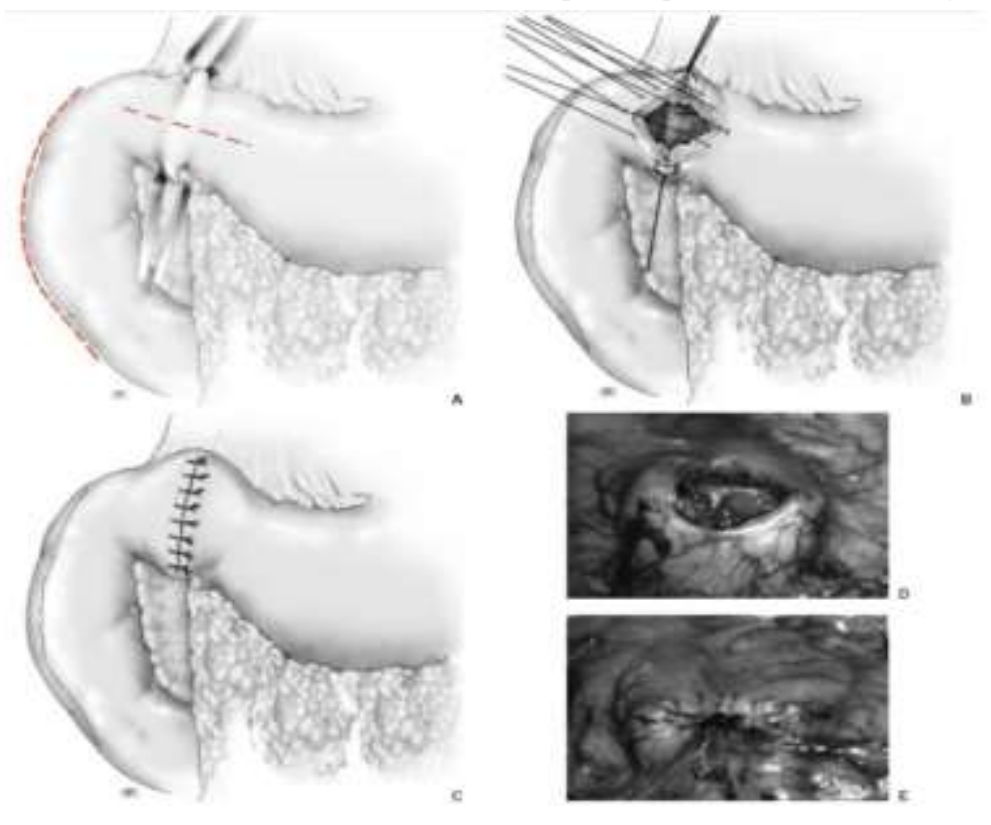

Figure 4 Pyloroplasty of Heineck Mikulicz. A. Horizontal antro-pyloro-duodenal opening; B, C. Vertical suture with separate extramucous stitches; D. Incision on the pylorus and verticalization of the incision; E. Heineck-Mikulicz transverse suture. Source [11]

\section{Conclusion}

Although rare, caustic pyloric stenosis by sodium hydroxide ingestion is still possible and should be considered when evaluating damage caused by the latter.

\section{Compliance with ethical standards}

\section{Disclosure of conflict of interest}

There is no conflict of interest.

\section{Statement of informed consent}

Informed consent was obtained from all individual participants included in the study. 


\section{References}

[1] Contini S, Scarpignato C. Caustic injury of the upper gastro intestinal tract: A comprehensive review World J Gastroenterol. 2013; 19 (25): 3918-30.

[2] Stephen WB, Boto SD. Epidemiology of paediatric surgical admissions to a government referral hospital in the Gambia. Bulletin of the World Health Organization. 2000; 78:1330-6.

[3] Sarioglu-buke A, Corduk N, Atesci F. A different aspect of corrosive ingestion in children: Socio-demographic characteristics and effect of family functioning. Int J Pediatr Otorhinolaryngol. 2006;70:1791-8.

[4] Mirza B, Ijaz L, Husnain M, Sheikh A. Accidental ingestion of hydrochloric acid causing acute gastric perforation in a child. Jour of surg Pakistan. 2011; 16:45-6.

[5] Quenu, Petit. Des sténoses cicatricielles du pylore consécutives a l'ingestion de liquides caustiques. Rev. de chir. Paris.1902; 25:51-67:176-195.

[6] Naik RR, Vadivelan M. Corrosive poisoning. Indian Jour of clin pract.2012;23:131-4

[7] Mirji P, Joshi C, Mallapur A, GVishwanath, Emmi S. Management of corrosive Injuries of the upper gastrointestinal tract. Jcdr. 2011; 5: 944-7.

[8] Arul GS, Parikh D. Oesophageal Replacement in Children. Ann R Coll Surg Engl. 2008; 90:7-12

[9] Quenot JP, Coatmeur O, Doise JM. Traitement laparoscopique de l'ulcère duodénal par vagotomie tronculaire et pyloro-myotomie. Gastroenterol Clin Biol, 2004; 28:192-4.

[10] Souza V. Effect of $\mathrm{NaCl}$ and $\mathrm{HCl}$ concentrations on primary $\mathrm{pH}$ measurement for the certification of standard materials. Braz. arch. biol. technol. 2006; 49: 79-86.

[11] Samaja M. Le stenosi cicatriziali del piloro secondarie ad ingestione di caustica. Riforma med. 1930. 46:202-206.

[12] Yoely A, Yusri D J, Yorva S. Pyloric stenosis caused by ingestion of corrosive agents: a case report. Jurnal Human Care. $2021 ; 6$ (1): 39-44

[13] Fiogbe MA, Bankole-sanni R, Tambo F, Kanate G, Soh MBA, Mobiot ML. Le traitement par dilatation des sténoses caustiques de l'œsophage chez l'enfant au CHU de Treichville. Bénin Médical. 2006; 34:25-26.

[14] Betalli P, Falchetti D, Giuliani S, Pane A, Dall'oglio L, DE Angelis GL et al. Caustic ingestion in children: Is endoscopy always indicated. The results of an Italian multicenter observational study. Gastrointestinal Endoscopy. 2008; 68:434-9.

[15] Sadio Y, Togo S, Ouattara MA, Sankare I, Tu ZL, Maiga IB, et al. Les sténoses caustiques de l'œsophage à l'hôpital du Mali, Ampleur, gravité et place de la dilatation en chirurgie. Chirurgie Thoracique et Cardio-Vasculaire. 2014; 18(4): 230-236. 